\title{
EstuPlan: Methodology for the development of creativity in the resolution of scientific and social problems
}

Sergio Astudillo ${ }^{1}$, Laura de Díez ${ }^{1}$, Marina García ${ }^{1}$, Nora Ortega ${ }^{1}$, Víctor Rodríguez ${ }^{1}$, Sabah Alzahrani ${ }^{1}$, Raquel Alonso ${ }^{1}$, Adolfo Ávalos', Blanca Cifuentes ${ }^{1}$, Alberto Esteban', Aránzazu Gómez ${ }^{1}$, Luisa Martín', Soledad Martín², Elena Pérez-Urría1, Beatriz Pintos ${ }^{1}$, Teresa Solís ${ }^{1}$, Margarita Torres ${ }^{2}$, Gema Aguado', Darío Aguilar ${ }^{1}$, Cristina Alonso', Elena Anaya ${ }^{1}$, Raquel Arnal', Lara Bejarano', Marina Briones ${ }^{1}$, Silvia Cantaragiu', Celia Casado ${ }^{1}$, Beatriz Cuevas ${ }^{1}$, María de Hoz $^{1}$, Clara García ${ }^{1}$, Elva García ${ }^{1}$, Ángela Gómez ${ }^{1}$, Carlos González ${ }^{\mathbf{1}}$, Carolina Herrera ${ }^{1}$, Iulia Konarieva ${ }^{1}$, Manuel Lambea ${ }^{1}$, Alba Liébana ${ }^{1}$, Paula Losada ${ }^{1}$, Laura Manrique ${ }^{1}$, María Marín ${ }^{1}$, Ana Martínez ${ }^{1}$, María Montañés ${ }^{1}$, Laura Montecino ${ }^{1}$, Paula Murillo ${ }^{1}$, Sara Poyatos ${ }^{1}$, Maialen Pujana ${ }^{1}$, Celia Ruiz ${ }^{1}$, Laura Sánchez ${ }^{1}$, Rocío Sánchez ${ }^{1}$, Lucía SánchezArchidona $^{1}$, Verónica Villar ${ }^{1}$, Elena Zamorano ${ }^{1}$, Antonio Santos ${ }^{1}$

${ }^{1}$ Department of Genetics, Physiology and Microbiology, Universidad Complutense de Madrid, Spain. ${ }^{2}$ Department of Pharmacology, Pharmacognosy and Botany, Universidad Complutense de Madrid, Spain.

\begin{abstract}
Creative thinking is necessary to generate novel ideas and solve problems. "EstuPlan" is a methodology in which knowledge and creativity converge for the resolution of scientific problems with social projection. It is a training programme that integrates teachers, laboratory technicians and PhD students, master and undergraduate students which form working groups for the development of projects. Projects have a broad and essential scope and projection in terms of environmental problems, sustainable use of natural resources, food, health, biotechnology or biomedicine. The results show the success of this significant learning methodology using tools to develop creativity in responding to scientific and social demand for problem-solving to transfer academic knowledge to different professional environments. Bioplastics, Second Life of Coffee, LimBio, Algae oils, Ecomers, Caring for the life of your crop and Hate to Deforestate are currently being developed.
\end{abstract}

Keywords: Creativity; Problem solving; Entrepreneurship; EstuPlan. 
EstuPlan: Methodology for the development of creativity in the resolution of scientific and social problems.

\section{Introduction}

There are at least two different ways of thinking: (a) convergent thinking, which makes emphasis on replication of existing data and adaptation of known responses to new situations in a more or less logical way, and (b) divergent thinking, characterized by flexibility and originality in the production of new ideas. It is a fact that many essential attributes of creativity are not developed, or are lost, in the traditional master classes or exhibition, which is why it is important to create environments suitable for the development of creativity, environments that seek to generate relevant ideas and unusual that bring new visions that change the focus of the problems or redefine the problems to provide innovative visions and therefore solutions.

There seems to be a certain consensus on defining creativity as the ability to produce novel ideas and/or products and useful or appropriate (Amabile and Kramer, 2011). Originality and usefulness are the two criteria that are considered essential for "something", idea or product to be considered creative (Runco and Jaeger, 2012).

Creative thinking presents four characteristic traits that are measured: 1. Fluidity: to produce a large number of ideas; their measurement is made considering the total number of "relevant" responses. 2. Flexibility: to produce very varied answers belonging to different fields; the number of different categories of answers is measured. 3. Originality: to produce ideas far from the obvious and established; it is measured according to the curiosity of the answers. 4. Elaboration: aptitude to develop, enlarge and embellish ideas; the measure will depend on the number of additional details used. Therefore, in order to produce original ideas, it is useful to generate many ideas (fluidity) and different types of ideas (flexibility) because this increases the likelihood that original ideas will be generated being able to measure divergent thinking skills, fluency, flexibility original ideas, being able to measure divergent thinking skills, fluency, flexibility and originality.

Creative thinking can be considered one of the key competences with widespread effects in the 21st century. It is what has made it possible to fly to the moon, create art, develop computers or cure diseases. Creativity is not only recognized in sciences and arts, but has also been shown to play an important role in the resolution of everyday and extraordinary problems. In addition to its function in solving problems, creativity allows to be flexible; cognitive flexibility provides the ability to cope with the opportunities and changes that are part of our complex world undergoing rapid change. Creativity is found in the agendas of the business leaders and policy-makers throughout the world. For example, 2009 was declared the Year of Creativity and Innovation in order to facilitate the ability to think creatively across the population (European Commission 2008). The creativity is a skill that 
must be developed in all disciplines and in all intellectual, scientific and social fields (Kampilis and Berki, 2014).

\section{EstuPlan: Objectives and Value Proposition}

EstuPlan is an original project of innovation and improvement of the quality of teaching developed by an interdisciplinary group that includes among its members teachers, administration and services technical staff and $\mathrm{PhD}$ and master students of the Complutense University of Madrid. It consists of the development of projects by undergraduate students, projects in which knowledge and creativity converge in the resolution of scientific problems with social projection and related to the use of natural resources. On the other hand, EstuPlan proposes a new system for the training of students in which teachers, laboratory technicians, $\mathrm{PhD}$, master and undergraduate students are organized in work groups (Fig. 1).

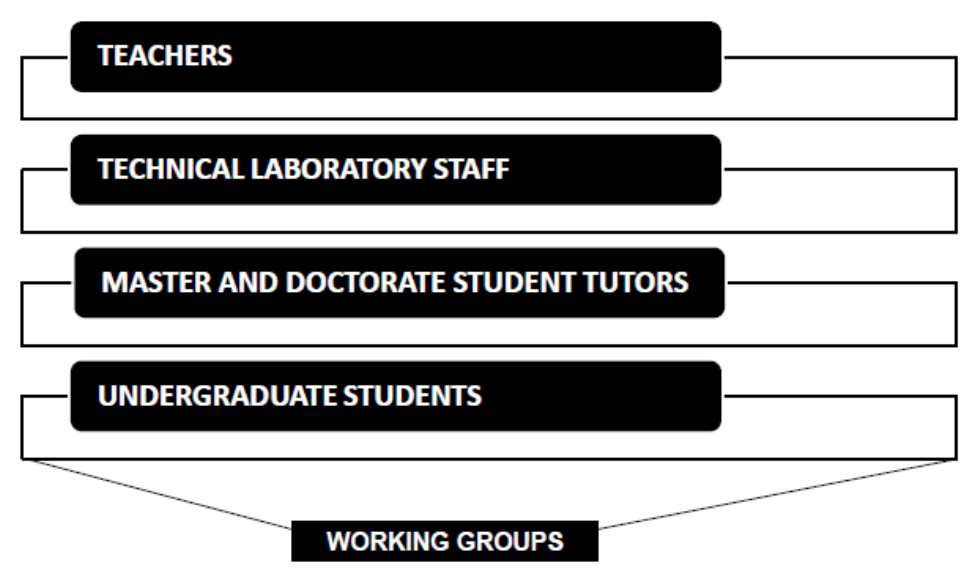

Figure 1. Actors in EstuPlan

Teachers, laboratory technicians and "older" students (PhD and Master) advise and help "younger" students of 3rd Grade for the definition and selection of problems, the search and definition of solutions, the genesis of ideas derived from the problem-solution binomial, and finally the elaboration of a project. It presents an innovative and useful methodology in the framework of today's society, the world of work, and in the context of entrepreneurship, areas that demand problem-solving skills and creativity to transfer academic knowledge to new application environments. EstuPlan is basic training and learning to transfer science and put scientific solutions at the service of society. It is the social projection of science. It 
EstuPlan: Methodology for the development of creativity in the resolution of scientific and social problems.

is a call and a new offer to universitary students. It is transferable to any field of knowledge.

The general objectives of EstuPlan are defined in the following terms:

1. To stimulate and develop the potential and creative attitudes of university students taking into account the dimensions of originality, fluidity, flexibility and elaboration that characterize creativity.

2. Applying knowledge to problem solving in new or unfamiliar environments within broader contexts of innovation, genesis and development of ideas.

3. Integrate and project specific knowledge in broader and innovative contexts.

The concrete objectives that help to achieve the general objectives are defined in the following terms:

4. To apply different methods to generate new ideas, or restructure existing ideas, and create novel alternative solutions to problems related to the sustainable use of natural resources.

5. To carry out a project.

6. To work collaboratively in multidisciplinary working groups.

7. To incorporate this activity into the training activities of $\mathrm{PhD}$ students.

Regarding the value proposition, EstuPlan responds to needs detected in undergraduate students such as:

a. To focus on problems, in this case of a scientific nature and with social relevance.

b. To solve problems in a significant way based on knowledge.

c. To give relevance to their studies and especially to their projection, and to them as students, in very close times and professional environments.

d. To take the decisive step from "knowing" to "doing".

On the other hand, EstuPlan is an extraordinary opportunity to integrate in the studies of degree methodologies and tools in line with current academic and profession. Therefore, it can be said that EstuPlan is a response to the above needs by providing a new environment because the working groups it proposes contain students, student tutors, technicians, and teachers who organize and guide the meetings and projects development (Fig. 2). 


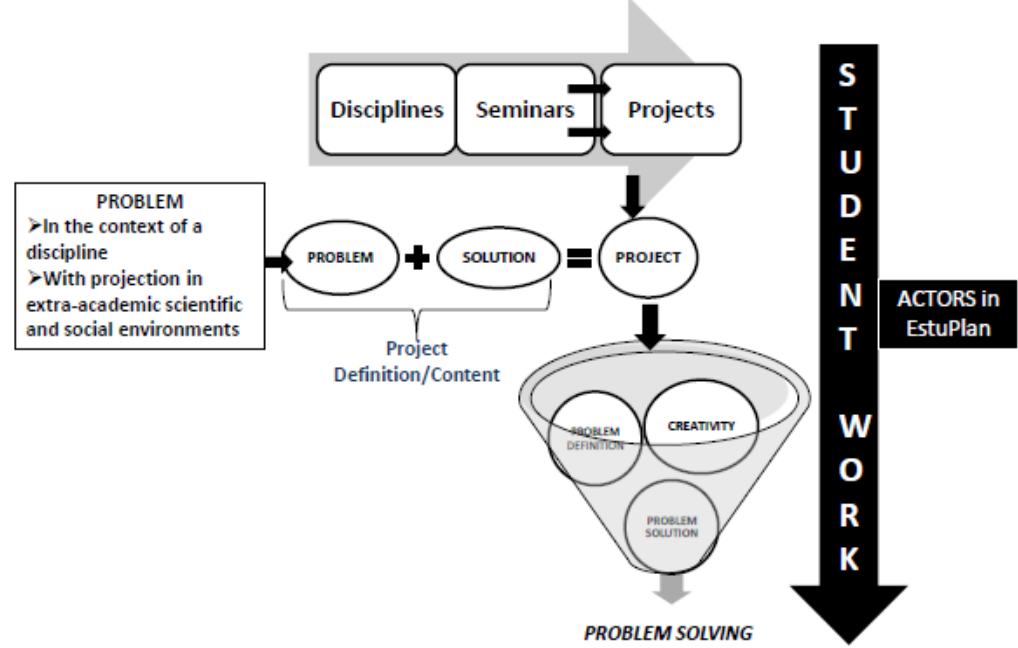

Figure 2. EstuPlan Goals

\section{Methodology and work planning}

EstuPlan follows a methodology that promotes creative output by providing training, techniques, media and exercises to promote creativity and the ability to problem solving. Use the SCAMPER tool, a thinking method directed towards an object, idea, event, situation or problem based on the brainstorming technique and developed by Eberle (2008). Each step of this method is directed by questions that represent the stimulus that leads to effective thinking (Buser et al., 2011). SCAMPER is the acronym for $\mathrm{S}=$ substitute, $\mathrm{C}=$ Combine, $\mathrm{A}=$ Adapt, $\mathrm{M}=$ Modify, $\mathrm{P}=\mathrm{Swap}, \mathrm{E}=$ Delete and $\mathrm{R}=$ Reorder. SCAMPER is a tool that allows this, promotes and activates creativity and skills to solve problems. At SCAMPER all questions are valid and all ideas should be considered.

EstuPlan is developed in one academic year and in two phases. Phase 1 consists of organizing the course and integrating EstuPlan into an academic discipline by proposing topics or problems related to that discipline. Phase 2 consists of three steps: step 1 of formation of the working groups, presentation of the members, project and the work plan; step 2 of development of the work plan by scheduling the face-to-face and online meetings; step 3 final of the project in which an infographics and a video of the project is made and a day of public exposition is established (Fig. 3). The final project in the form of infographics contains the following items: 1. Title, 2. Justification: description of the problem and proposed solution, 3. Project Structure: recipients, value proposition, media and/or necessary resources, 4 . Relevance, scientific and social projection of the project. 
EstuPlan: Methodology for the development of creativity in the resolution of scientific and social problems.

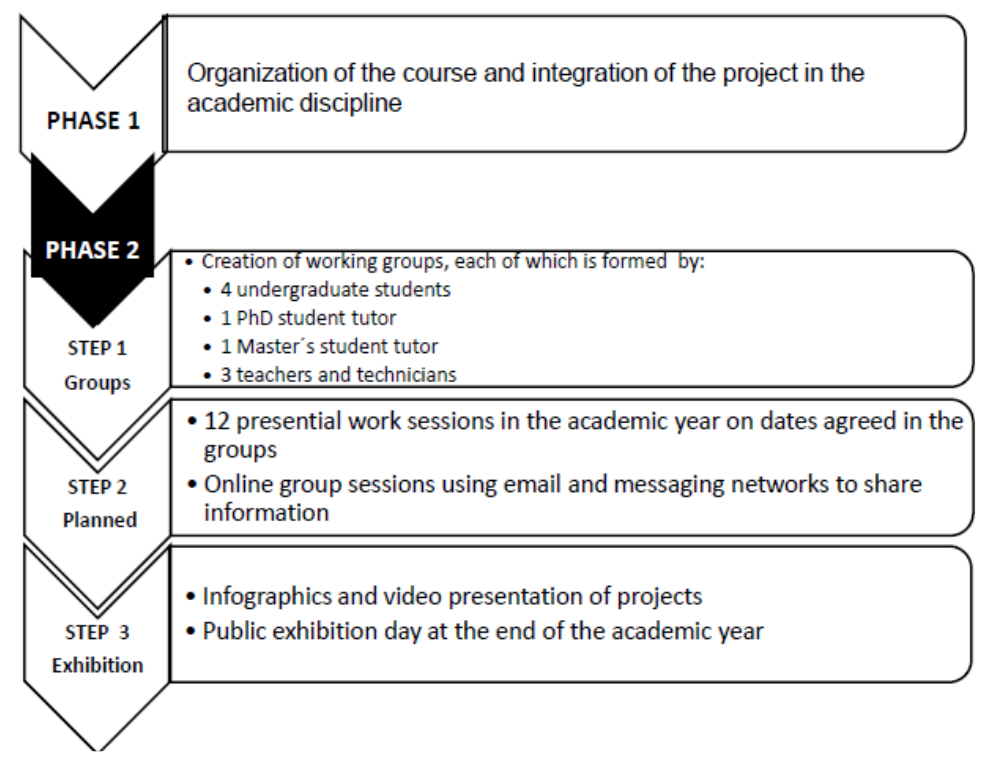

Figure 3. Work Plan

\section{Results, Impact and Indicators}

EstuPlan is a proposal of methodology and innovative tools in the context of Bachelor studies to develop creativity and the ability to solve problems in any field of knowledge. In particular and as example, this project is developed in the scientific field of Plant Physiology applied to environmental problems, the uses and applications of plant resources in different industries (Bioenergy, Biomedicine, etc.) and the use of agro-food waste. The following projects are currently under development: Bioplastics, Second Life of Coffee, LimBio, Algae oils, Ecomers, Caring for the life of your crop and Hate to Deforestate.

The results obtained are relevant in terms of creativity and development of novel and innovative projects, some of which have been recognized and awarded in competitions for ideas, project development and entrepreneurship such as Explorer-Complutense University of Madrid Space (https://explorerbyx.org/) or Compluemprende (https://www.ucm.es/compluemprende/)

Indicators to measure the impact in relation to the objectives are as follows: 1. Follow-up of the work plan: attendance at scheduled sessions and development of the meetings, activities agreed and committed, and on time; 2. Degree of satisfaction of the undergraduate students measured through a questionnaire with scale $1-5$, on (a) information received about and participation in EstuPlan, (b) accessibility to the teachers, technicians and student tutors, c) degree of coordination and guidance received, d) orientation and projection of the work 
carried out in Estuplan in other innovation environments and/or entrepreneurship, e) global assessment; 3. Degree of satisfaction of the teachers, technicians and student tutors, suggestions and proposals of improvement to expand its implementation.

\section{Conclusions}

Problem focus, creativity, problem solving and innovation are necessary and applicable skills in scientific and social environments, considering also that scientific problems have an enormous impact, involvement and social projection.

Consequently, EstuPlan can be developed in any subject or with students of any field of knowledge, either from Experimental Sciences, Health Sciences or Humanities. It is also interesting to extend EstuPlan to other non-university educational levels by adapting the contents.

Finally, EstuPlan's activities and methodology are also the seed of the entrepreneurship.

\section{Acknowledgements}

The authors express special thanks to Vicerrectorado de Calidad and Compluemprende (Universidad Complutense de Madrid), and to Explorer (Santander Universidades and Centro Internacional Santander Emprendimiento-CISE).

\section{References}

Amabile, T..M. \& Kramer, S..J. (2011). The progress principle. Using small wins to ignite joy, engagement, and creativity at work. Harvard Business Review Press.

Buser, K.. J., Buser, J. T., Gladding, T. S. \& Wilkerson, J. (2011). The creative counselor: using the scamper model in counselor training. Journal of Creativity in Mental Health, 6(4), 256-273.

Compluemprende, Oficina Complutense del Emprendedor https://www.ucm.es/compluemprende/

Eberle, B. (2008). Scamper: Creative games and activities for imagination development. Waco: Prufrock Press.

European Comission (2008) http://europa.eu/rapid/press-release_IP-08 482 en.htm?locale $=\mathrm{fr}$

Explorer, Build a Better Future https://explorerbyx.org/

Kampilis, P. \& Berkis, E. (2014). Nurturing creative thinking. International Bureau of Education (UNESCO)-International Academy of Education https://unesdoc.unesco.org/ark:/48223/pf0000227680

Runco, M. A. \& Jaeger, G. J. (2012). The standard definition of creativity. Creativity Research Journal, 24 (1), 92-96. doi: 10.1080/10400419.2012.650092 